\title{
Effect of Spinning Parameters on Thick, Thin Places and Neps of Rotor Spun Yarn
}

\author{
Md. Reazuddin Repon ${ }^{1 *}$, Rajib Al Mamun1, Selim Reza², Mithun Kumer Das ${ }^{3}$, Tarikul Islam ${ }^{4}$ \\ ${ }^{1}$ Department of Textile Engineering, Khwaja Yunus Ali University, Sirajgonj, Bangladesh \\ ${ }^{2} \mathrm{PM}$ Group, Narayanganj, Bangladesh \\ ${ }^{3}$ Department of Textile Engineering, Daffodil International University, Dhaka, Bangladesh \\ ${ }^{4}$ Department of Textile Engineering, Port City International University, Chittagong, Bangladesh \\ Email:*reazmbstu@gmail.com, rajibtexmbstu@kyau.edu.bd, selim@pmgroupbd.com, mithungoutam@yahoo.com, \\ matarikul.islam2014@gmail.com
}

How to cite this paper: Repon, Md.R., Al Mamun, R., Reza, S., Das, M.K. and Islam, T. (2016) Effect of Spinning Parameters on Thick, Thin Places and Neps of Rotor Spun Yarn. Journal of Textile Science and Technology, 2, 47-55.

http://dx.doi.org/10.4236/jtst.2016.23007

Received: August 5, 2016

Accepted: August 27, 2016

Published: August 30, 2016

Copyright $\odot 2016$ by authors and Scientific Research Publishing Inc.

This work is licensed under the Creative

Commons Attribution International

License (CC BY 4.0).

http://creativecommons.org/licenses/by/4.0/

\begin{abstract}
Defect free yarn is a great demand for spinner, knitter, and weaver and also other textile personnel because numerous end products from knit apparels to woven fabrics, from towels to sheets and from carpets to industrial fabrics characteristics significantly depend on the physical properties of yarn. The qualities of rotor yarn are really directed by spinning parameters. The aim of this study is to observe the effect of spinning parameters such as rotor diameter and speed on thick, thin places and neps of yarn in rotor spinning process. 0.11 sliver hank of $100 \%$ cotton was used to produce $12 \mathrm{Ne}$ yarn. $65 \%$ virgin cotton and $35 \%$ wastage cotton were mixed together. The positive impact of spinning parameters on yarn properties were accessed by thick places, thin places and neps. Results indicate that the yarn qualities were improved with increasing of rotor speed and rotor diameter. The rotor diameter was settled to $43 \mathrm{~mm}$ while rotor speed fluctuated from 35,000 to $45,000 \mathrm{rpm}$ and rotor speed was fixed to $35,000 \mathrm{rpm}$ while rotor diameter across contrasts from 43 $\mathrm{mm}$ to $66 \mathrm{~mm}$.
\end{abstract}

\section{Keywords}

Rotor Spinning, Rotor Diameter, Rotor Speed, Thick Places, Thin Places, Neps

\section{Introduction}

Rotor spinning is considered as most suitable and successful spinning process among many open-end spinning methods [1]. This spinning principle is significantly acceptable for high production of yarn by using low to medium grade 
cotton even from wastage at relatively lower cost than any other existing spinning technology [2]. It is common in rotor spinning that the yarns are spun from wastage or by mixing and blending wastage to the normal raw material. This indicates that profits are better and the raw material, namely wastes from spinning mill, is relatively cheaper to give better returns [1].

Rotor spinning gives a new era to produce more uniform, fuller, aerated and regular in strength of cotton yarn [3]. The volume of production on rotor spinning has increased in recent years [4]. Due to the considerable reduction in space and personnel, the rotor spinning system is rising [5] [6].

Rotor spinning is a recognized spinning system mainly for medium and course counts. The yarn characteristics of rotor spun yarn are affected by many factors related to raw material, machine parameters and processing parameters also.

Many researchers have already investigated the effect of rotor and carding parameters on yarn quality from different outlooks [7] [8] [9] [10] [11]. The results of several investigations have revealed that the physical and mechanical properties of yarn extensively concerned by machine parameters [12] [13] [14]. Rotor yarns are less irregular compared to the ring spun yarn because of multiple doubling or back doubling of fibres in the rotor groove. In addition, rotor spun yarns are not as affected by roller drafting wave as ring yarns [6]. No work has been observed on the yarn properties on the basis of thick, thin places and neps produced from $65 \%$ virgin cotton, $10 \%$ droppings $1,10 \%$ droppings $2,10 \%$ noil and $5 \%$ pneumafil of $12 \mathrm{Ne}$ rotor yarn.

The main object of this work is to produce better quality yarn. In this study, the effect of rotor speed from 35,000 to $45,000 \mathrm{rpm}$ and rotor diameter from 43 to $66 \mathrm{~mm}$ on $100 \%$ cotton yarn properties in terms of thick, thin places and neps were systematically investigated. The quality cotton yarn was produce by using rotor spinning system that can be used for weaving and knitting fabrics. In order to authenticate this work, yarns were spun at three selected rotor speeds (i.e. 35,000, 40,000 and 45,000 rpm) and three rotor diameter (i.e. 43, 54 and 66 $\mathrm{mm}$ ). Rotor diameter was unchanged to $43 \mathrm{~mm}$ while yarns were spun with speed variation. Similarly, rotor speed was fixed to $35,000 \mathrm{rpm}$ whereas yarns were spun with diameter variation.

\section{Materials and Methods}

\subsection{Materials}

The slivers of 0.11 hanks were collected from Akij Spinning Mills Limited, manikgonj, Bangladesh. The sliver was produced from $65 \%$ virgin cotton and $35 \%$ wastage. The wastage were composed of $10 \%$ droppings $1,10 \%$ droppings 2 , $10 \%$ noil and 5\% pneumafil. Table 1 states the cotton fibre properties used in this experimentation. The properties of cotton fibre were assessed by Uster-HVI spectrum instrument (Switzerland). 


\subsection{Methods}

\subsubsection{Spinning Process}

BD 200RN, Elitex, Czech Republic type rotor spinning machine was used in this experiment to produce yarn. Various types of yarns were produced based on different variables. Rotor speed changed from 35,000 to $45,000 \mathrm{rpm}$ at constant rotor diameter of $43 \mathrm{~mm}$ and rotor diameter raised from $43 \mathrm{~mm}$ to $66 \mathrm{~mm}$ at constant rotor speed of 35,000 rpm. Firstly, drawn slivers were feed through a sliver guide via a feed roller and feed plate to rapidly rotating opening roller. The rotating teeth of the opening roller comb out the separate fibers from the sliver clamped between feed plate and feed roller. Then the fibers were feed to inside wall of the rotor after completing action in transport channel. The fibres moved forward to the rotor groove from the conical rotor wall by centrifugal forces in the rapidly rotating rotor. Finally, the yarn formed in the rotor is continuously taken off by the delivery shaft and the pressure roller through the nozzle and the draw off tube and wound onto a cross wound package [2] [15]. Figure 1 and Figure 2 represents the basic working principle of rotor spinning system and flow diagram of yarn preparation respectively.

Table 1. Properties of cotton fibre.

\begin{tabular}{cc}
\hline Quality parameters & Value \\
\hline Spinning Consistency Index & 138 \\
Micronaire $(\mu \mathrm{g} /$ inch) & 3.00 \\
Uniformity Index (\%) & 80.0 \\
Short Fibre Index (\%) & 8.2 \\
Length $(\mathrm{mm})$ & 28.00 \\
Strength (g/tex) & 30.4 \\
Elongation (\%) & 6.0 \\
Maturity Index & 0.87 \\
Moisture (\%) & 7.1 \\
\hline
\end{tabular}

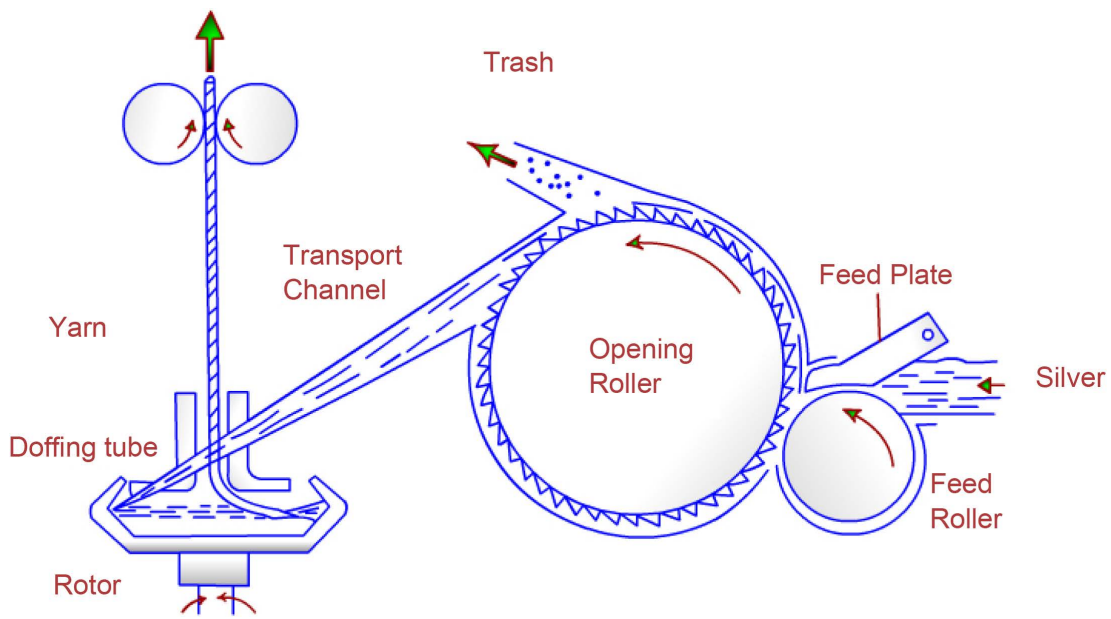

Figure 1. Basic working principle of rotor spinning system [16]. 


\subsubsection{Testing of Samples}

Uster Tester-5 was used to determine the thick places, thin places and neps of the yarn at a speed of $450 \mathrm{~m} / \mathrm{min}$. The sensitivity setting was $-50 \%$ for thin places, $+50 \%$ for thick places and $+280 \%$ for neps. Thin places indicate the mass reductions, thick places indicate the mass increase and neps indicates the increase of short mass. Average of ten tests was taken for final result at each trial. All experiments were performed at temperature $20^{\circ} \mathrm{C} \pm 2{ }^{\circ} \mathrm{C}$ and relative humidity $65 \% \pm 2 \%$ [17]. Yarn count was determined through the digital auto sorter-5 linked with computer system, which gives direct reading. Figure 3 characterize the thick, thin places and neps of rotor yarn.

\section{Results and Discussion}

Rotor spinning is a very fast rising spinning technique for the production of coarse and medium count yarns. This is so because of its higher productivity, better product quality and profitability. Considering such factors the present research work was initiated to study the effect of rotor speed and rotor diameter upon the yarn quality. Yarn faults in the shape of thin, thick places and neps on the external appearance of yarns and the obtained products are decisive to minimize. The resultant data presented in different figures is discussed here.

\subsection{Thick Places}

The Figure 4 and Figure 5 are representing the impact of rotor speed and rotor

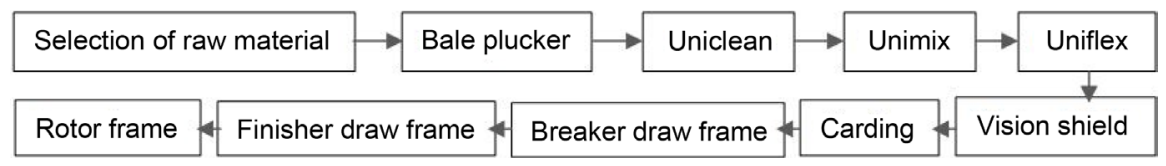

Figure 2. Flow diagram of yarn preparation.

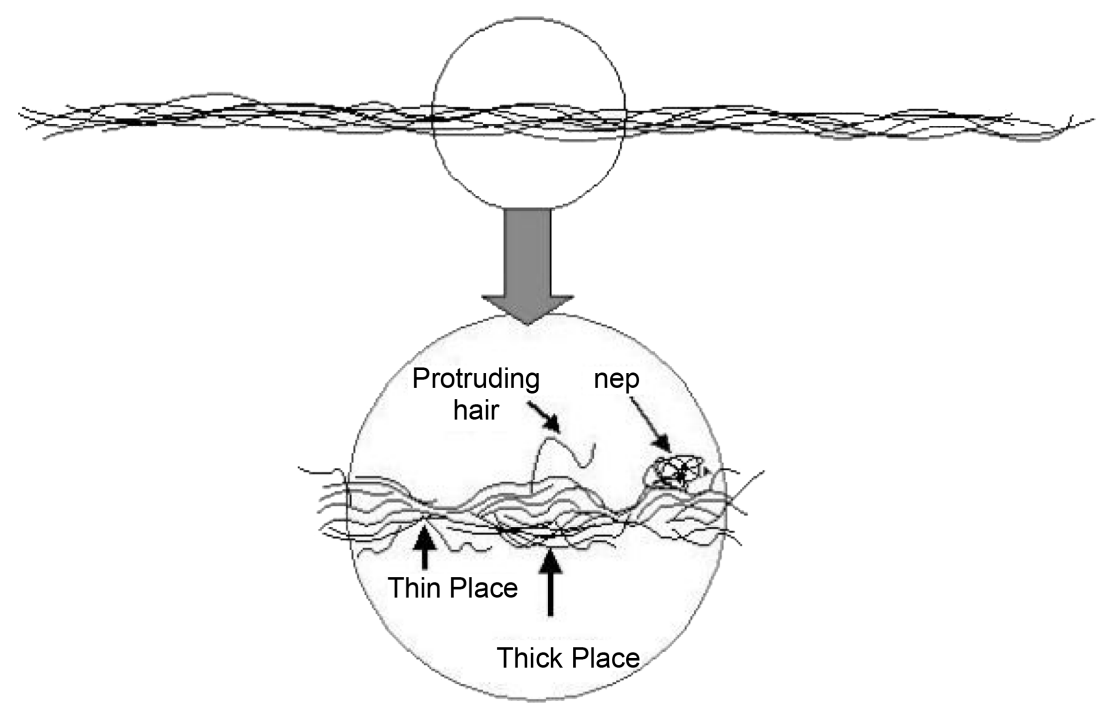

Figure 3. Thick, thin places and neps of yarn. 


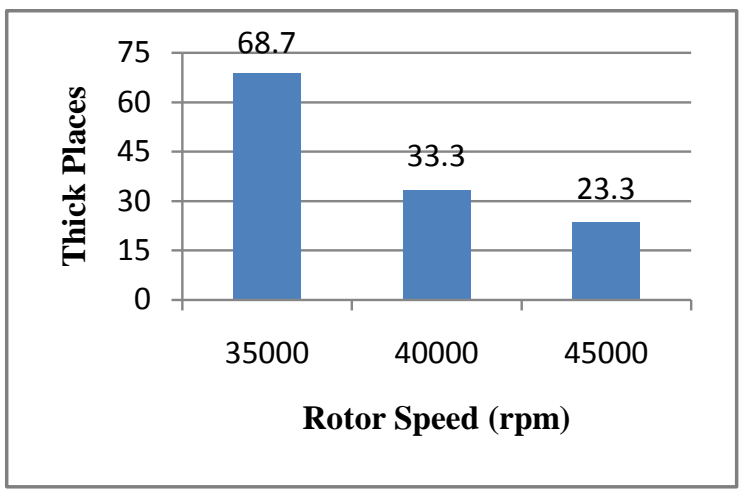

Figure 4. Effect of rotor speed on yarn thick places at rotor diameter of $43 \mathrm{~mm}$.

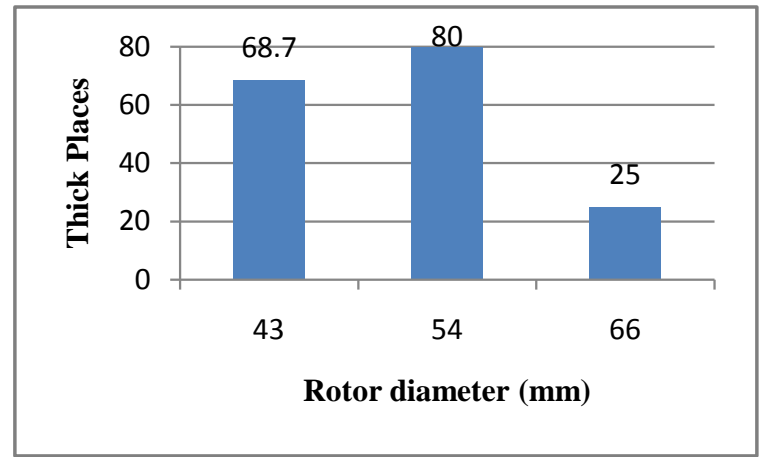

Figure 5. Effect of rotor diameter on yarn thick places at rotor speed of $35,000 \mathrm{rpm}$.

diameter on thick places of the yarn respectively. The rotor speed and rotor diameter has positive effect on yarn thick places. The effect of rotor speed on yarn thick places was studied at constant rotor diameter of $43 \mathrm{~mm}$ and effect of rotor diameter was checked at constant rotor speed of 35,000 rpm. Thick places were decreased with the increment of rotor speed and rotor diameter. Concerning thick places, the order of samples were found as like 35,000 >40,000 >45,000 for rotor speed and $54 \mathrm{~mm}>43 \mathrm{~mm}>66 \mathrm{~mm}$ for rotor diameter. In case of speed variation, the thick places were decreased $51.53 \%$ and $66.08 \%$ respectively for the samples produced from the rotor speed of $40,000 \mathrm{rpm}$ and $45,000 \mathrm{rpm}$ as compared to the sample from $35,000 \mathrm{rpm}$. It has been also found that at rotor diameter variation, the thick places were increased $16.45 \%$ and decreased $63.61 \%$ respectively for the samples produced from the rotor diameter $54 \mathrm{~mm}$ and 66 $\mathrm{mm}$ compared to the sample produced from $43 \mathrm{~mm}$.

\subsection{Thin Places}

The analyzed data on thin places of yarn for rotor speed and rotor diameter were shown in Figure 6 and Figure 7 correspondingly. The values of thin places were decreased with the increment of rotor speed. No chronological impacts were noticed due to increase of rotor diameter. Regarding thin places, the order of samples 


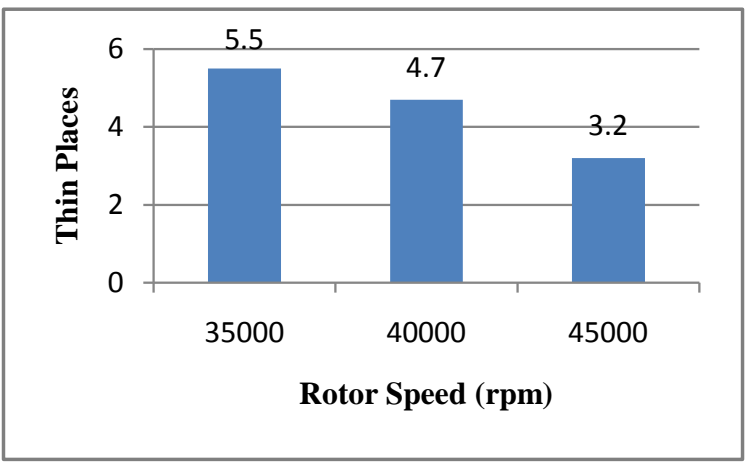

Figure 6. Effect of rotor speed on yarn thin places at rotor diameter of $43 \mathrm{~mm}$.

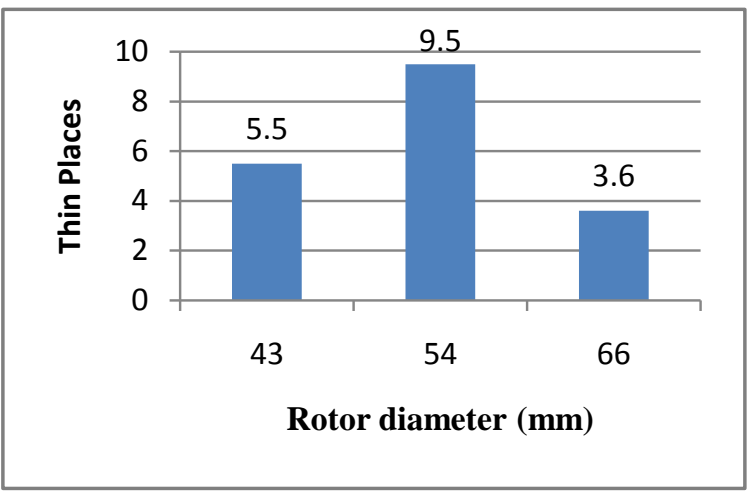

Figure 7. Effect of rotor diameter on yarn thin places at rotor speed of $35,000 \mathrm{rpm}$.

were found as 35,000 rpm $>40,000 \mathrm{rpm}>45,000 \mathrm{rpm}$ for rotor speed variation and $54 \mathrm{~mm}>43 \mathrm{~mm}>66 \mathrm{~mm}$ for rotor diameter variation respectively. The thin places were decreased $14.54 \%$ and $41.82 \%$ for the samples produced from the rotor speed of 40,000 rpm and 45,000 rpm as compared to the sample from $35,000 \mathrm{rpm}$. It has been also found that at rotor diameter variation, the thin places were decreased $34.55 \%$ for the samples produced from rotor diameter 66 $\mathrm{mm}$ compared to the sample produced from $43 \mathrm{~mm}$. Oppositely, the values was increased $72.73 \%$ for for the samples produced from rotor diameter $54 \mathrm{~mm}$. The result revealed that 9.5 was the highest value of yarn thin places.

\subsection{Neps}

Figure 8 and Figure 9 illustrates the effect of rotor speed and rotor diameter on neps of yarn. Rotor speed and rotor diameter has positive and negative impact on yarn neps. Regarding neps, the order of samples were found 35,000 rpm > $45,000>40,000$ for variation of rotor speed and $54 \mathrm{~mm}>43 \mathrm{~mm}>66 \mathrm{~mm}$ for variation of rotor diameter. The neps was decreased $34.73 \%$ for the sample produced from 40,000 rpm and 25.07\% decreased for the sample from 45,000 rpm compared to the sample from $35,000 \mathrm{rpm}$ rotor speed at constant rotor diameter 


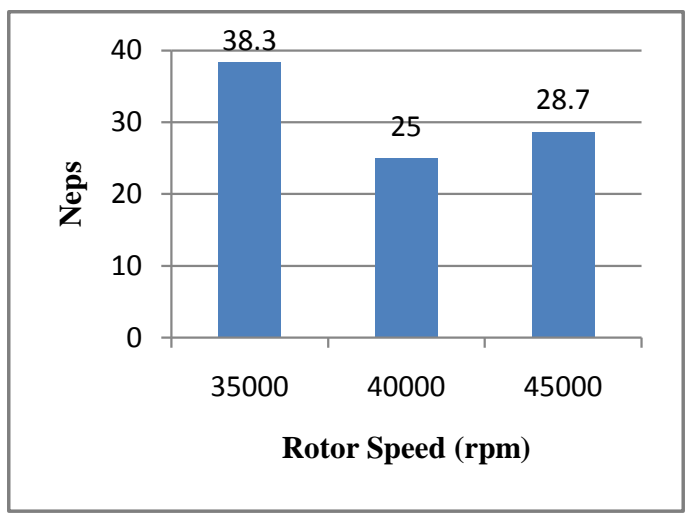

Figure 8. Effect of rotor speed on yarn neps at rotor diameter of $43 \mathrm{~mm}$.

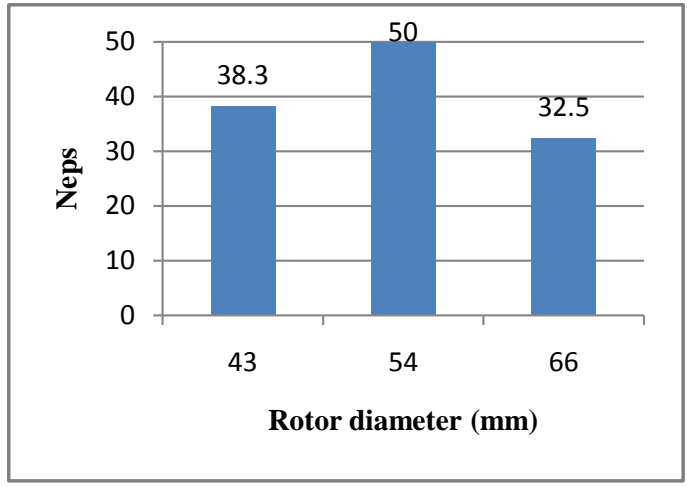

Figure 9. Effect of rotor diameter on yarn neps at rotor speed of $35,000 \mathrm{rpm}$.

of $43 \mathrm{~mm}$. It was also found that the neps were $15.14 \%$ decreased for the sample produced from $66 \mathrm{~mm}$ rotor diameter and $30.55 \%$ increased for the sample produced from $54 \mathrm{~mm}$ compared to the sample of $43 \mathrm{~mm}$ rotor diameter at constant rotor speed 35,000 rpm. The highest neps were recorded for the yarn of 54 $\mathrm{mm}$ rotor diameter.

\section{Conclusions}

Rotor-spun yarns have established firmly in fields of application for woven and knitted fabrics. Rotor-spun yarns could be utilized effectively where the particular properties of the rotor-spun yarns corresponded particularly closely to the requirements of the end products. Terry products and upholstery fabrics are the main applications for rotor-spun yarns in the home textiles sector. Also worth mentioning as end products using rotor spun yarns are socks and sweaters in the clothing sector, sheets and upholstery fabrics in the home textile sector, as well as technical textiles.

Noteworthy effect of rotor speed and rotor diameter on the yarn thick, thin places and neps in rotor spinning was studied. At constant rotor diameter of 43 
$\mathrm{mm}$, the yarn qualities were improved i.e. thick, thin places and neps were decreased with increase of rotor speed from 35,000 to 45,000 rpm. Conversely, analogous scenario observed due to augmentation of rotor diameter from 43 to $66 \mathrm{~mm}$ at constant rotor speed of 35,000 rpm. The yarn quality tends to deteriorate i.e. thick, thin places and neps were increased when the rotor diameter increases from 43 to $54 \mathrm{~mm}$. Further work could be done on producing quality yarn of various counts from other natural, synthetic and blends fibres to justify this analysis. It also could be checked by changing others spinning parameters.

\section{References}

[1] Khan, M.K.R. and Rahman, H. (2015) Study of Effect of Rotor Speed, Combing-Roll Speed and Type of Recycled Waste on Rotor Yarn Quality Using Response Surface Methodology. IOSR Journal of Polymer and Textile Engineering (IOSR-JPTE), 2, 47-55.

[2] Klein, W. (1995) Manual of Textile Technology. The Textile Institute, 1-6.

[3] Nawaz, S.M., Jamil, N.A., Iftikhar, M. and Farooqi, B. (2003) How Does Open-End Processing Variables Effect Imperfections for Different Yarn Count? Pakistan TeXtile Journal, 22-26.

[4] Ishtiaque, S.M. (1992) Spinning of Synthetic Fibres and Blends on Rotor-Spinning Machine. Indian Journal of Fibre and Textile Research, 17, 224-230.

[5] Ahmed, S., Syduzzaman, M., Mahmud, M.S., Ashique, S.M. and Rahman, M.M. (2015) Comparative Study on Ring, Rotor and Air-Jet Spun Yarn. European Scientific Journal, 11, 411-424.

[6] Rameshkumar, C., Anandkumar, P., Senthilnathan, P., Jeevitha, R. and Anbumani, N. (2008) Comparative Studies on Ring Rotor and Vortex Yarn Knitted Fabrics. Autex Research Journal, 8, 100-105.

[7] Manohar, J.S., Rakshit, A.K. and Balasubramanian, N. (1983) Influence of Rotor Speed, Rotor Diameter, and Carding Conditions on Yarn Quality in Open-End Spinning. Textile Research Journal, 53, 497-503. https://doi.org/10.1177/004051758305300811

[8] Salhotra, K.R. and Balasubramanian, P. (1985) Influence of Carding Technique on Yarn Tenacity Response to Increasing Rotor Speed. Textile Research Journal, 55, 381-382. https://doi.org/10.1177/004051758505500612

[9] Sengupta, A.K., Vijayaraghavan, N. and Singh, A. (1983) Studies on Carding Force between Cylinder and Flats in a Card: Part III-Carding Parameters, Sliver Quality and Carding Force. Indian Journal of Fibre \& Textile Research, 8, 68.

[10] Al Mamun, R., Repon, Md.R., Islam, M.T. and Motaleb, K.Z.M.A. (2017) Promising Effect of Processing Parameters on Yarn Properties in Rotor Spinning. Manufacturing Science and Technology, 4, 11-15.

[11] Jackowska-Strumiłło, L., Cyniak, D., Czekalski, J. and Jackowski, T. (2007) Quality of Cotton Yarns Spun Using Ring-, Compact-, and Rotor-Spinning Machines as a Function of Selected Spinning Process Parameters. Fibres \& Textiles in Eastern Europe, 15, 24-30.

[12] Özdemir, H. and Oğulata, R.T. (2011) Comparison of the Properties of a Cotton Package Made of Vortex (MVS) and Open-End Rotor Yarns. Fibres \& Textiles in Eastern Europe, 19, 37-42. 
[13] Ahmed, F., Saleemi, S., Rajput, A.W., Shaikh, I.A. and Sahito, A.R. (2014) Characterization of Rotor Spun Knitting Yarn at High Rotor Speeds. Technical Journal, 19, 73-78.

[14] Hasani, H. and Tabatabaei, S.A. (2011) Optimizing Spinning Variables to Reduce the Hairiness of Rotor Yarns Produced from Waste Fibres Collected from the Ginning Process. Fibres \& Textiles in Eastern Europe, 19, 21-25.

[15] http://www.rieter.com/en/rikipedia/articles/rotor-spinning/the-importance-of-roto r-spinning/the-principle-of-rotor-spinning/

[16] http://nptel.ac.in/courses/116102038/33

[17] ASTM D (1776) Standard Practice for Conditioning Textiles for Testing. American Society for Testing and Materials, Annual Book of ASTM Standards, Vol. 7, No. 1, ASTM International, West Conshohocken.

Submit or recommend next manuscript to SCIRP and we will provide best service for you:

Accepting pre-submission inquiries through Email, Facebook, LinkedIn, Twitter, etc. A wide selection of journals (inclusive of 9 subjects, more than 200 journals)

Providing 24-hour high-quality service

User-friendly online submission system

Fair and swift peer-review system

Efficient typesetting and proofreading procedure

Display of the result of downloads and visits, as well as the number of cited articles Maximum dissemination of your research work

Submit your manuscript at: http://papersubmission.scirp.org/

Or contact jtst@scirp.org 